Article

\title{
Regulatory Effects of Fisetin on Microglial Activation
}

Jing-Yuan Chuang ${ }^{1, \dagger}$, Pei-Chun Chang ${ }^{2, \dagger}$, Yi-Chun Shen ${ }^{1}$, Chingju Lin ${ }^{3}$, Cheng-Fang Tsai ${ }^{4}$, Jia-Hong Chen ${ }^{5}$, Wei-Lan Yeh ${ }^{6}$, Ling-Hsuan Wu ${ }^{7}$, Hsiao-Yun Lin ${ }^{8}$, Yu-Shu Liu ${ }^{7}$ and Dah-Yuu Lu ${ }^{9,10, *}$

1 Department of Medical Laboratory Science and Biotechnology, China Medical University, Taichung 40402, Taiwan; E-Mails: jychuang@mail.cmu.edu.tw (J.-Y.C.); syciac@gmail.com (Y.-C.S.)

Department of Bioinformatics, Asia University, Taichung 41354, Taiwan;

E-Mail: pcchang@asia.edu.tw

3 Department of Physiology, School of Medicine, China Medical University, Taichung 40402,

Taiwan; E-Mail: clin33@mail.cmu.edu.tw

4 Department of Biotechnology, Asia University, Taichung 41354, Taiwan;

E-Mail: tsaicf@asia.edu.tw

5 Department of General Surgery, Taichung Tzu Chi Hospital, Buddhist Tzu Chi Medical Foundation, Taichung 42743, Taiwan; E-Mail: guns5150@ms27.hinet.net

6 Department of Cell and Tissue Engineering, Changhua Christian Hospital, Changhua 500, Taiwan; E-Mail: ibizayeh0816@hotmail.com

7 Graduate Institute of Basic Medical Science, China Medical University, Taichung 40402, Taiwan; E-Mails: lulu80620@yahoo.com.tw (L.-H.W.); yushuliu220@gmail.com (Y.-S.L.)

8 Department of Life Sciences, National Chung Hsing University, Taichung 402, Taiwan; E-Mail: lingir1831@hotmail.com

9 Graduate Institute of Neural and Cognitive Sciences, China Medical University, Taichung 40402, Taiwan

10 Department of Photonics and Communication Engineering at Asia University, Taichung 41354, Taiwan

$\dagger$ These authors contributed equally to this work.

* Author to whom correspondence should be addressed; E-Mail: dahyuu@mail.cmu.edu.tw; Tel.: +886-4-2205-3366 (ext. 8206); Fax: +886-4-2207-1507.

Received: 30 April 2014; in revised form: 13 June 2014 / Accepted: 18 June 2014 / Published: 26 June 2014

Abstract: Increasing evidence suggests that inflammatory processes in the central nervous system that are mediated by microglial activation play a key role in neurodegeneration. 
Fisetin, a plant flavonol commonly found in fruits and vegetables, is frequently added to nutritional supplements due to its antioxidant properties. In the present study, treatment with fisetin inhibited microglial cell migration and ROS (reactive oxygen species) production. Treatment with fisetin also effectively inhibited LPS plus IFN- $\gamma$-induced nitric oxide (NO) production, and inducible nitric oxide synthase (iNOS) expression in microglial cells. Furthermore, fisetin also reduced expressions of iNOS and NO by stimulation of peptidoglycan, the major component of the Gram-positive bacterium cell wall. Fisetin also inhibited the enhancement of LPS/IFN- $\gamma$ - or peptidoglycan-induced inflammatory mediator IL (interlukin)-1 $\beta$ expression. Besides the antioxidative and anti-inflammatory effects of fisetin, our study also elucidates the manner in fisetin-induced an endogenous anti-oxidative enzyme HO (heme oxygenase)-1 expression. Moreover, the regulatory molecular mechanism of fisetin-induced HO-1 expression operates through the PI-3 kinase/AKT and p38 signaling pathways in microglia. Notably, fisetin also significantly attenuated inflammation-related microglial activation and coordination deficit in mice in vivo. These findings suggest that fisetin may be a candidate agent for the development of therapies for inflammation-related neurodegenerative diseases.

Keywords: microglia; neuroinflammation; neurodegeneration; fisetin; cytokine

\section{Introduction}

Microglial activation leads to neuroinflammatory responses that exert both beneficial and detrimental effects, including host defense and tissue repair processes [1,2]. During neuroinflammatory periods, activated microglia are able to clear debris or invading pathogens, and produce neurotrophic factors which modulate the microenvironment [3]. When sensing ATP leaks from an injury site, microglia transform to a more motile state and migrate to the site of damage [4], which causes neuroinflammation and subsequent neurodegeneration. Excessive inflammatory mediators and oxidative stress in the CNS are associated with the pathogenesis of neurodegeneration [5,6]. In pathological neuroinflammatory conditions, microglial activation results in expression of new proteins like inducible nitric oxide synthase (iNOS) which have been shown to cause neuronal damage [7-10]. It has been reported that iNOS triggers NO production by activated microglia, which further aggravate the pathological processes in neurodegeneration [11]. The expressions of the inflammation-related enzymes iNOS have also been reported in the striatum of Parkinson disease patients [12]. Although inflammatory mediators are necessary for normal neuronal cell functions, the microglial response must be tightly regulated to avoid over-activation and neurotoxic consequences [13]. Interleukin-1 beta (IL-1 $\beta$ ) is a major pro-inflammatory cytokine that increases expression of adhesion molecules and synthesis of cytotoxins $[14,15]$. Microglia activation and neuronal degeneration are co-presence of IL-1 $\beta$ in Alzheimer's disease [16]. Moreover, IL-1 $\beta$ was observed in cerebrospinal fluid of multiple sclerosis patients, suggesting a possible link between inflammation and neurodegeneration [17].

Many natural products, such as flavonoids, are potential therapeutic agents recognized for their antioxidant activity [18]. Flavonoids are low-molecular-weight natural polyphenolic compounds found 
in many fruits and vegetables. It has been reported that flavonoids exert many biological functions $[19,20]$. Fisetin (3,3',4',7-tetrahydroxyflavone; Figure 1A), a high Trolox-equivalent antioxidant, is found in strawberry, persimmon, grape and cucumber [21]. Due to it being a hydrophobic compound, fisetin easily penetrates cell membranes accumulating in cells to exert its antioxidative effects [22], with wide-ranging biological activities including antiaging, anti-inflammatory, neuroprotection and anticancer effects [23,24]. Previous reports have demonstrated the protective effects of fisetin on microglial activation and subsequent neurotoxicity [25]. After oral administration of fisetin could also pass the blood-brain barrier to exert neuroprotective and cognition-enhancing effects in animal model of CNS disorders [26] Importantly, fisetin attenuates postischemic immune cell infiltration and reduces infarct size after transient cerebral middle artery occlusion in mice [27]. Recent study also revealed that orally administered fisetin exerts neuroprotection against reactive gliosis and behavioral deficits in aluminum chloride-induced brain pathology model [28].

Figure 1. Effect of fisetin on microglial activation. (A) Chemical structure of fisetin. (B) Cell viability following fisetin treatment in BV-2 microglia. Cells were incubated with concentrations ranging from 1 to $5 \mu \mathrm{M}$ of fisetin for 60 min followed by treated with LPS $(10 \mathrm{ng} / \mathrm{mL})$ plus IFN- $\gamma(10 \mathrm{ng} / \mathrm{mL})$ for $24 \mathrm{~h}$, and cell viability was measured by the MTT assay. The results are expressed as mean \pm S.E.M. of three independent experiments. (C) Cells were pretreated with various concentrations of fisetin for $60 \mathrm{~min}$ followed by stimulation with $\mathrm{H}_{2} \mathrm{O}_{2}$ for $120 \mathrm{~min}$. ROS generation was determined using the fluorescence probes $\mathrm{H}_{2} \mathrm{DCFH}-\mathrm{DA}$ and examined by flow cytometry. The results are expressed as mean \pm S.E.M. from 3 to 4 independent experiments. ${ }^{*} p<0.05$ compared with the control group; ${ }^{\#} p<0.05$ compared with the $\mathrm{H}_{2} \mathrm{O}_{2}$ alone. (D) Cells were pre-incubated with various concentrations of fisetin $(1-5 \mu \mathrm{M})$ for 60 min followed by a 24-h treatment with ATP $(300 \mu \mathrm{M})$. In vitro migratory activities were examined using a cell culture insert system. The results are expressed as mean \pm S.E.M. from 3 independent experiments. ${ }^{*} p<0.05$ compared with the control group; ${ }^{*} p<0.05$ compared with the ATP alone. The migrated cells were visualized by phase-contrast imaging (Lower panel).

A<smiles>O=c1c(O)c(-c2ccc(O)c(O)c2)oc2cc(O)ccc12</smiles>

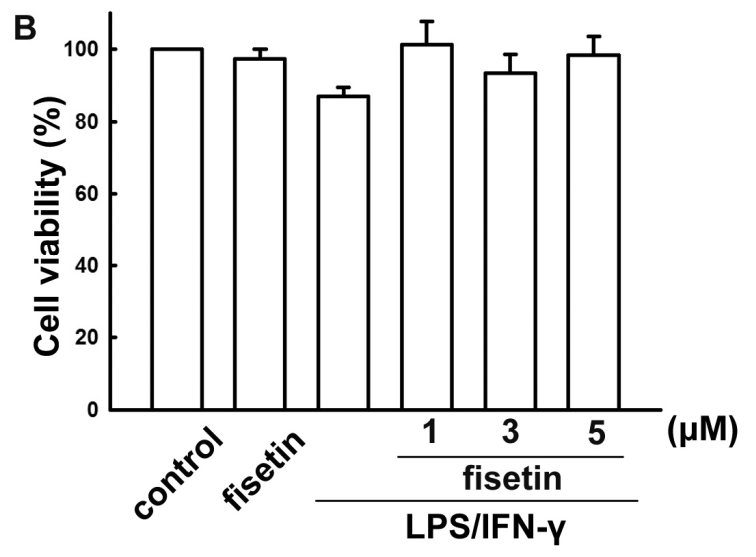


Figure 1. Cont.

C

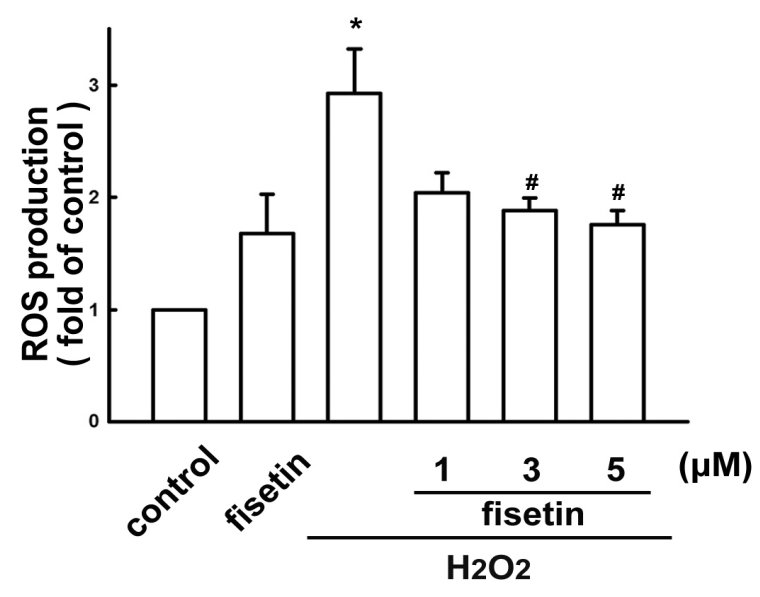

D
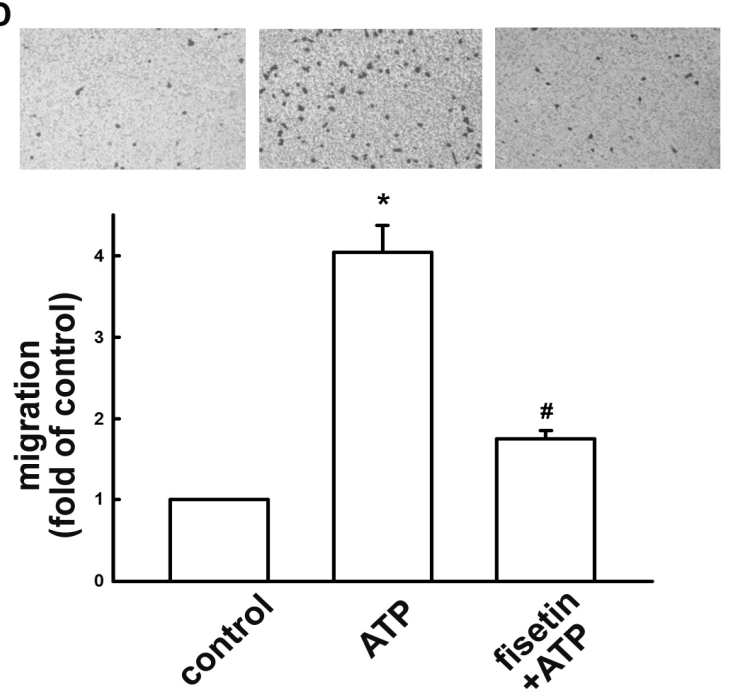

Heme oxygenase (HO), a cytoprotective enzyme, degrades heme to bilirubin, carbon monoxide, and iron [29,30]. Induction of HO-1 expression and related signal pathways exert anti-inflammatory effects in macrophages [31-33]. Recently, we have reported that neuroinflammatory responses can be repressed by HO-1 induction in microglia [34,35] and astrocytes [36], and that increased HO-1 expression protects neurons against neurotoxin-induced cell death [37,38]. Previous report shown that fisetin protects cells from oxidative-stress-induced death and induces HO-1 in human retinal pigment epithelial cells [39]. Fisetin also been reported to protect against hydrogen peroxide-induced oxidative stress through induction of HO-1 expression in human umbilical vein endothelial cells [40]. A recent study also reported that fisetin up-regulates HO-1 expression and interferes with reactive oxygen species production in macrophage-differentiated osteoclasts [41].

Although the beneficial effects of fisetin in brain have been investigated, the mechanism of regulation of microglia polarity has not yet been determined. In the present study, we addressed whether, in addition to inhibiting cytokine production, HO-1 expression also contributes to fisetin-regulated anti-inflammatory responses in microglial cells.

\section{Results}

\subsection{Fisetin Suppresses Neuroinflammatory Responses in Microglial Cells}

We used BV-2 microglia to study the effects of fisetin on neuroinflammatory responses. Concentrations ranging from 1 to $5 \mu \mathrm{M}$ fisetin were used in the current study. A colorimetric cell viability assay (MTT assay) confirmed that these concentrations did not affect cell viability (Figure 1B). $\mathrm{H}_{2} \mathrm{O}_{2}$ induced an increase in intracellular ROS levels, as shown by $\mathrm{H}_{2}$ DCF-DA staining which were analyzed by FACS detection assay (Figure 1C). Treatment with fisetin reduced $\mathrm{H}_{2} \mathrm{O}_{2}$-induced ROS productions (Figure 1C). Fisetin inhibited an ATP-induced increase in BV-2 microglial migratory activity (Figure 1D; upper panel). Representative micrographs of migrating cells are shown in Figure 1D (lower panel). To determine the effect of fisetin on iNOS/NO expression, cells were treated with different concentrations of fisetin $(1$ to $10 \mu \mathrm{M})$ and were stimulated with LPS plus IFN- $\gamma$. The supernatant of cell culture was 
then collected to determine NO production. Previously, we have demonstrated that peptidoglycan a major component of the Gram-positive bacterium cell wall, induces neuroinflammatory responses in microglial cells $[42,43]$. Hence, to further determine the effect of fisetin on nitric oxide production, BV-2 microglia were also stimulated with peptidoglycan. As shown in Figure 2A,B, fisetin effectively inhibited iNOS expression in a concentration-dependent manner following exposure to either LPS (10 ng/mL) plus IFN- $\gamma(10 \mathrm{ng} / \mathrm{mL})$ or peptidoglycan $(10 \mu \mathrm{g} / \mathrm{mL})$. Furthermore, fisetin also reduced LPS/IFN- $\gamma$ - and peptidoglycan-induced NO production (Figure 2C,D, respectively) in a concentration-dependent manner.

Figure 2. Inhibitory effect of fisetin on LPS/IFN- $\gamma$ or peptidoglycan-stimulated iNOS/NO expression. (A,C) BV-2 microglial cells were pretreated with different concentrations of fisetin $(1,3$, or $5 \mu \mathrm{M})$ for $60 \mathrm{~min}$ before application of LPS $(10 \mathrm{ng} / \mathrm{mL})$ plus IFN- $\gamma$ $(10 \mathrm{ng} / \mathrm{mL})$ for another $24 \mathrm{~h}$. (B,D) Cells were pretreated with different concentrations of fisetin $(1,3$, or $5 \mu \mathrm{M})$ for $60 \mathrm{~min}$ before application of peptidoglycan $(10 \mu \mathrm{g} / \mathrm{mL})$ for another $24 \mathrm{~h}$. Western blot analysis for iNOS $(\mathbf{A}, \mathbf{B})$ expression was performed on whole cell lysates. The quantitative results are shown in the bottom panels. The culture media were collected and analyzed NO production by a Griess reaction (C,D). iNOS or NO expression was significantly different between the LPS/IFN- $\gamma$ (or peptidoglycan) treated-group and the group treated LPS/IFN- $\gamma$ (or peptidoglycan) with fisetin. The results are expressed as mean \pm S.E.M. from 3 to 4 independent experiments. ${ }^{*} p<0.05$ compared with the control group; ${ }^{\#} p<0.05$ compared with the LPS/IFN- $\gamma$ or peptidoglycan treatment.
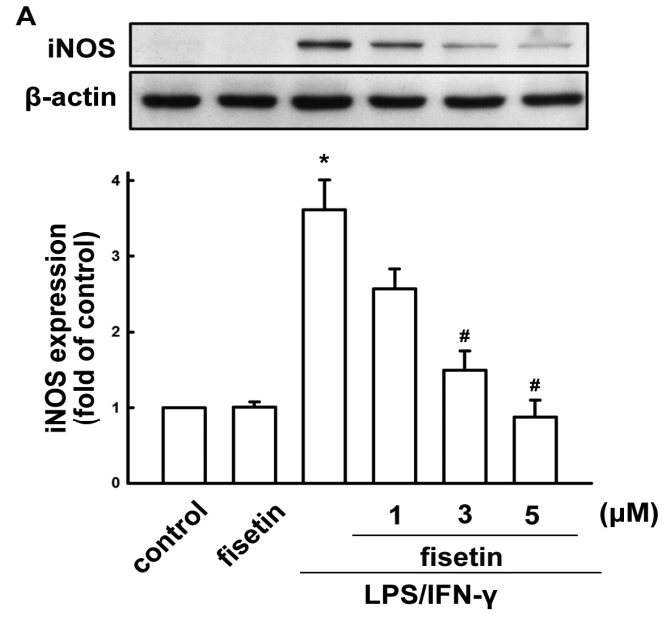

C

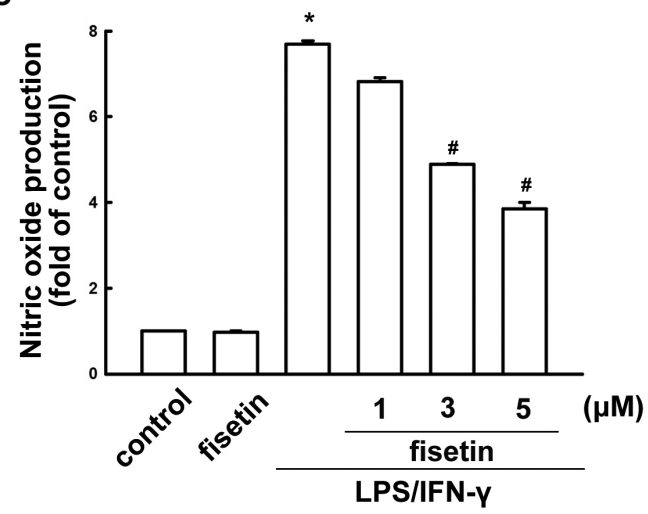

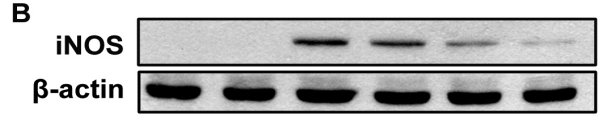

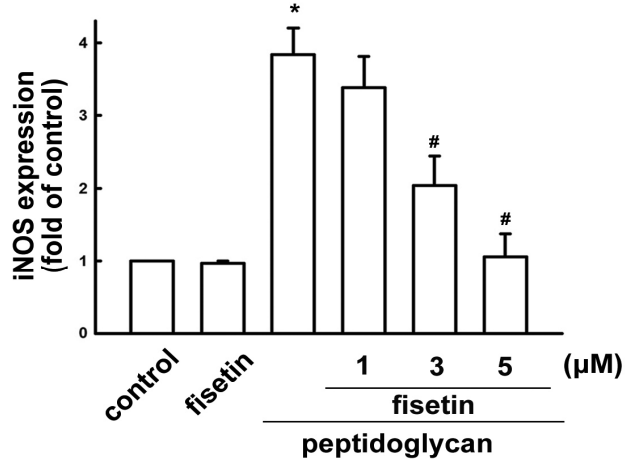

D

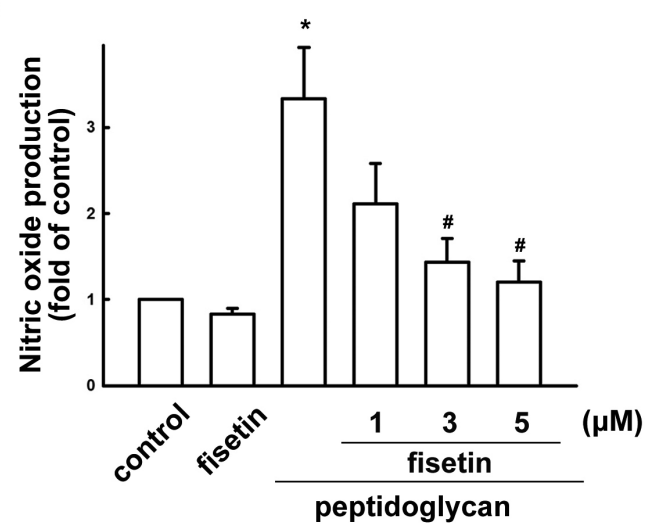


Notably, fisetin treatment alone did not affect iNOS or nitric oxide expression. We further analyzed the expression of inflammatory mediator using real-time PCR. BV-2 microglia were treated with different concentrations of fisetin (1 to $5 \mu \mathrm{M})$ and stimulated with LPS plus IFN- $\gamma$, or peptidoglycan for $6 \mathrm{~h}$. Fisetin potentiates a concentration-dependent suppression of iNOS when stimulating cells with LPS/IFN- $\gamma$ or peptidoglycan (Figure 3A,C, respectively). Similarly, treatment with fisetin also inhibited LPS/IFN- $\gamma$ - or peptidoglycan-induced IL- $1 \beta$ expression in a concentration-dependent manner (Figure 3B,D, respectively).

Figure 3. Inhibitory effect of fisetin on LPS/IFN- $\gamma$ - or peptidoglycan-stimulated iNOS and IL-1 $\beta$ expressions. BV-2 microglial cells were pretreated with different concentrations of fisetin $(1,3$, or $5 \mu \mathrm{M})$ for $60 \mathrm{~min}$, then challenged with LPS plus IFN- $\gamma(\mathbf{A}, \mathbf{B})$, or peptidoglycan $(\mathbf{C , D})$ for another $6 \mathrm{~h}$. The expression of iNOS and IL-1 $\beta$ were determined by real-time PCR. Cytokine expression was significantly different between the LPS/IFN- $\gamma$ (or peptidoglycan) alone and the LPS/IFN- $\gamma$ (or peptidoglycan) with fisetin groups. The results are expressed as mean \pm S.E.M. from 3 to 4 independent experiments. ${ }^{*} p<0.05$ compared with the control group; ${ }^{\#} p<0.05$ compared with the LPS/IFN- $\gamma$ treatment alone group.
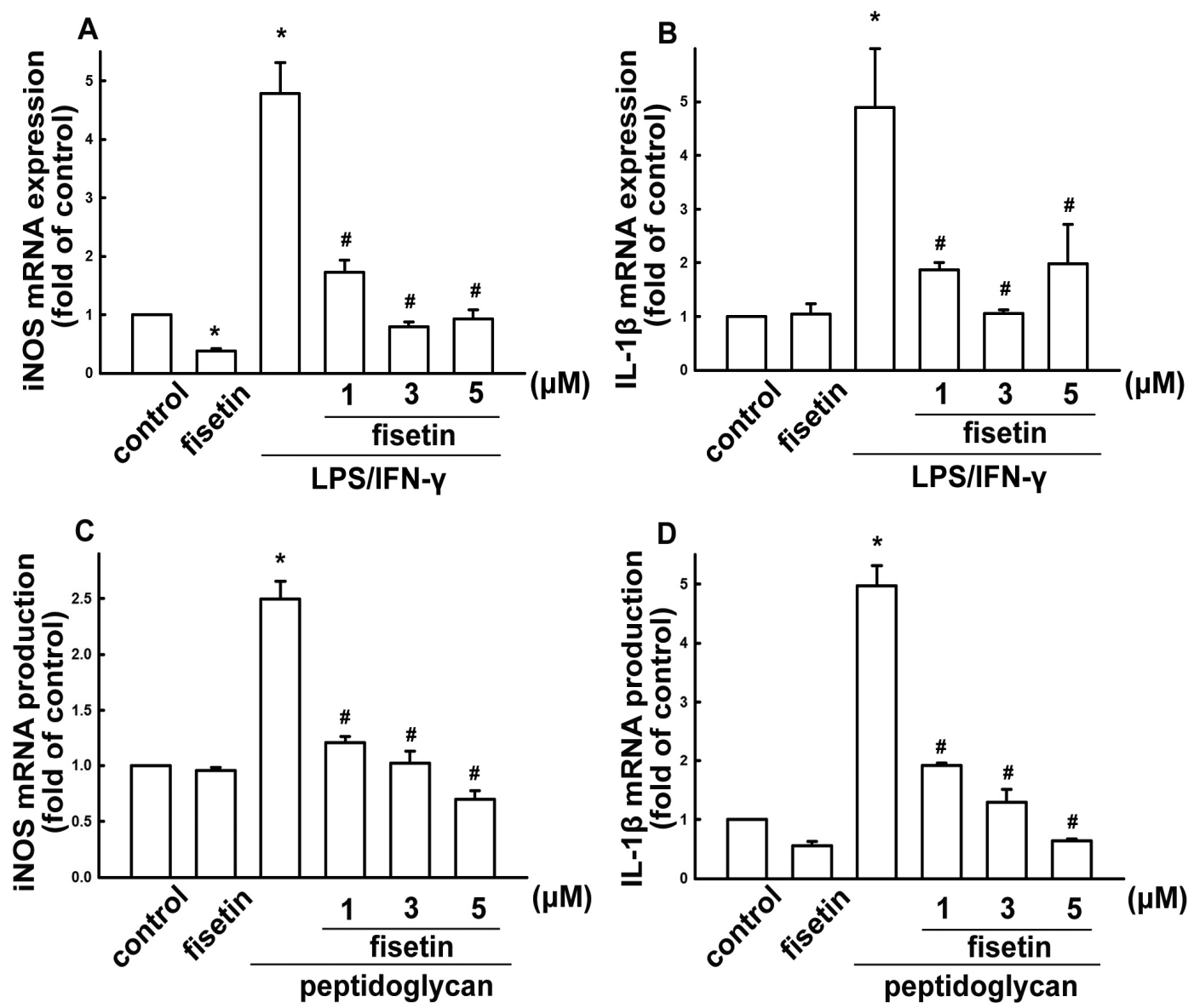

Next, we investigated regulation of STAT-1 protein on activatied effects in microglia. LPS plus IFN- $\gamma$ treatment resulted in STAT1 $\left(\mathrm{Tyr}^{701}\right.$ ) phosphorylation (Figure 4A). Treatment with different concentrations of fisetin ( 1 to $5 \mu \mathrm{M}$ ) attenuated LPS/IFN- $\gamma$-induced STAT1 $\left(\mathrm{Tyr}^{701}\right.$ ) phosphorylation (Figure 4A,B). In addition, fisetin reduced LPS/IFN- $\gamma$-induced JAK1 and JAK2 phosphorylation as 
well (Figure 4C,D, respectively). These results indicate that fisetin exerts anti-inflammatory effects in microglial cells.

Figure 4. Fisetin suppresses LPS/IFN- $\gamma$-induced STAT signaling pathways. BV-2 microglial cells were pretreated with fisetin $(1,3$, or $5 \mu \mathrm{M})$ for $60 \mathrm{~min}$, then exposed to LPS $(10 \mathrm{ng} / \mathrm{mL})$ plus IFN- $\gamma(10 \mathrm{ng} / \mathrm{mL})$ for another $60 \mathrm{~min}$. The phosphorylated levels of STAT-1, JAK1 or JAK2 were determined by western blot analysis, and the signal intensities were normalized to total protein expression. The results are expressed as mean \pm S.E.M. from 3 independent experiments. $* p<0.05$ compared with the vehicle control treatment group. ${ }^{\#} p<0.05$ compared with the LPS/IFN- $\gamma$ treatment alone group.

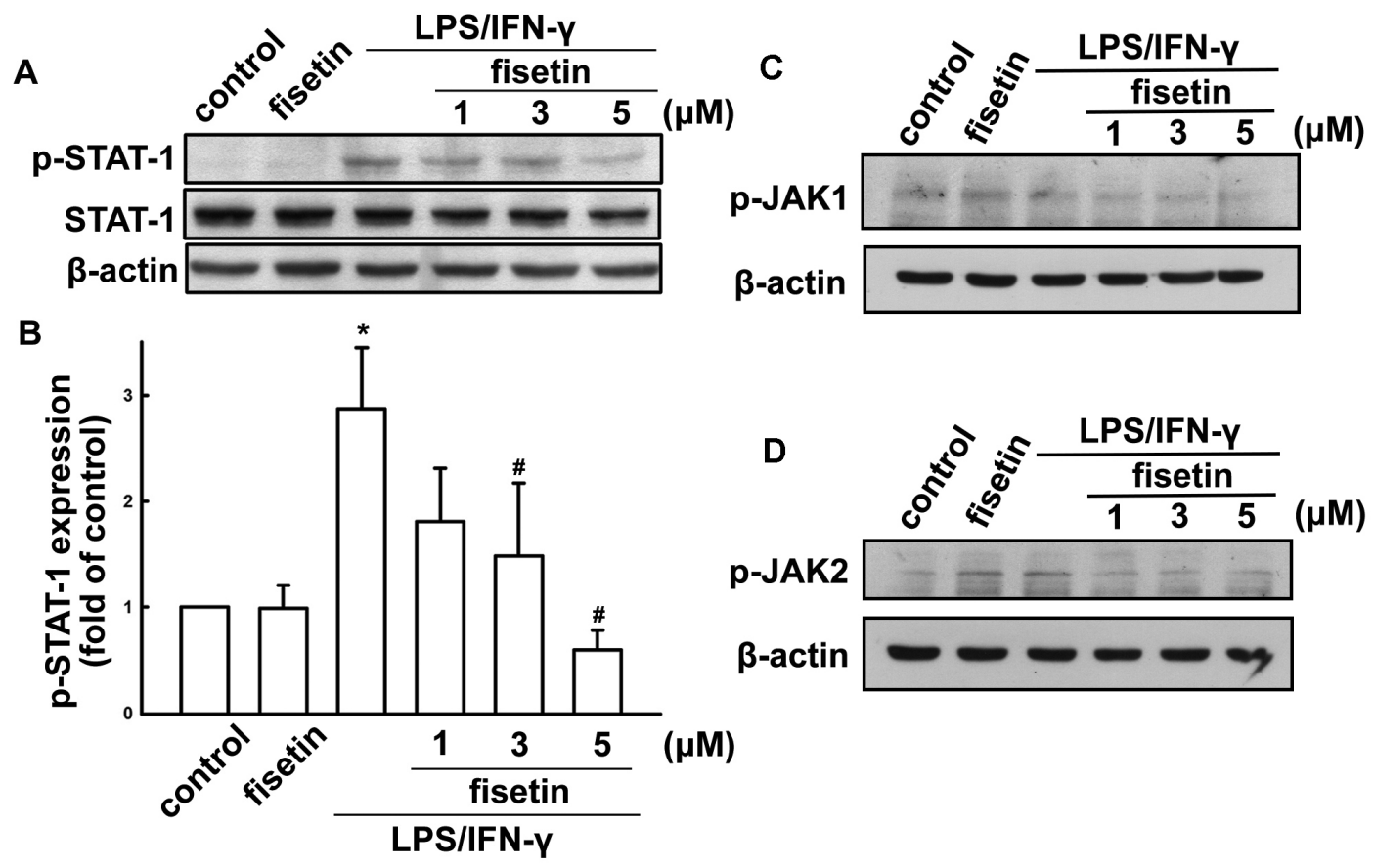

\subsection{Fisetin Induces HO-1 Up-Regulation in Microglia Cells}

Since HO-1 induction is known to participate in regulation of inflammatory responses, we investigated whether fisetin might lead to HO-1 induction. When BV-2 microglia were treated with fisetin for $24 \mathrm{~h}$, HO-1 levels increased in a concentration-dependent manner (Figure 5B). In addition, the HO-1 expression was further enhanced under fisetin treatment after LPS/IFN- $\gamma$ administration (Figure 5A). We further analyzed HO-1 mRNA expression induced by various concentrations of fisetin (Figure 5C). We then used a HO-1 activator CoPP IX to examine whether HO-1 expression participated in the anti-inflammatory pathways. As shown in Figure 5D, treatment with HO-1 activator increased HO-1 expression and abrogated LPS/IFN- $\gamma$-induced iNOS expression. Furthermore, treatment with CoPP IX also abrogated LPS/IFN- $\gamma$-induced nitric oxide production (Figure 5E). We further studied the signaling pathways involved in regulatory effects of fisetin on HO-1 in microglia. Treatment with p38 (SB203580) and PI3 kinase/Akt (LY294002) inhibitors, but not ERK (PD98059) and JNK (SP600125) inhibitors effectively antagonized fisetin-induced HO-1 expression (Figure 6A). As shown in Figure $6 \mathrm{~B}, \mathrm{C}$, incubation with p38 or PI3 kinase/Akt inhibitors reduced fisetin-induced HO-1 expression concentration-dependently. As shown in Figure 6D,E, fisetin increased p38 and Akt 
activation in a time-dependent manner as well. These results demonstrate that fisetin-induced anti-neuroinflammation may be regulated by HO-1 signaling pathway.

Figure 5. Effect of fisetin on HO-1 expression in microglia cells. (A) Cells were treated with fisetin, LPS $(10 \mathrm{ng} / \mathrm{mL})$ plus IFN- $\gamma(10 \mathrm{ng} / \mathrm{mL})$, or fisetin with LPS/IFN- $\gamma$ for $24 \mathrm{~h}$. Cells were treated with different concentrations of fisetin $(1,3$, or $5 \mu \mathrm{M})$ for $24 \mathrm{~h}(\mathbf{B})$ or $6 \mathrm{~h}$ (C). Whole cell lysates were subjected to western blot analysis for HO-1 protein expression (A,B). HO-1 mRNA expressions were analyzed by real time-PCR (C). Cells were treated with Copp IX for $60 \mathrm{~min}$, then challenged with LPS plus IFN- $\gamma$ for another $24 \mathrm{~h}$. The expression of iNOS and HO-1 were determined by western blot analysis (D). NO production was analyzed by Griess reaction $(\mathbf{E})$. The results are expressed as mean \pm S.E.M. from 3 to 4 independent experiments. ${ }^{*} p<0.05$ compared with the control group; ${ }^{\#} p<0.05$ compared with the LPS/IFN- $\gamma$ treatment alone group.

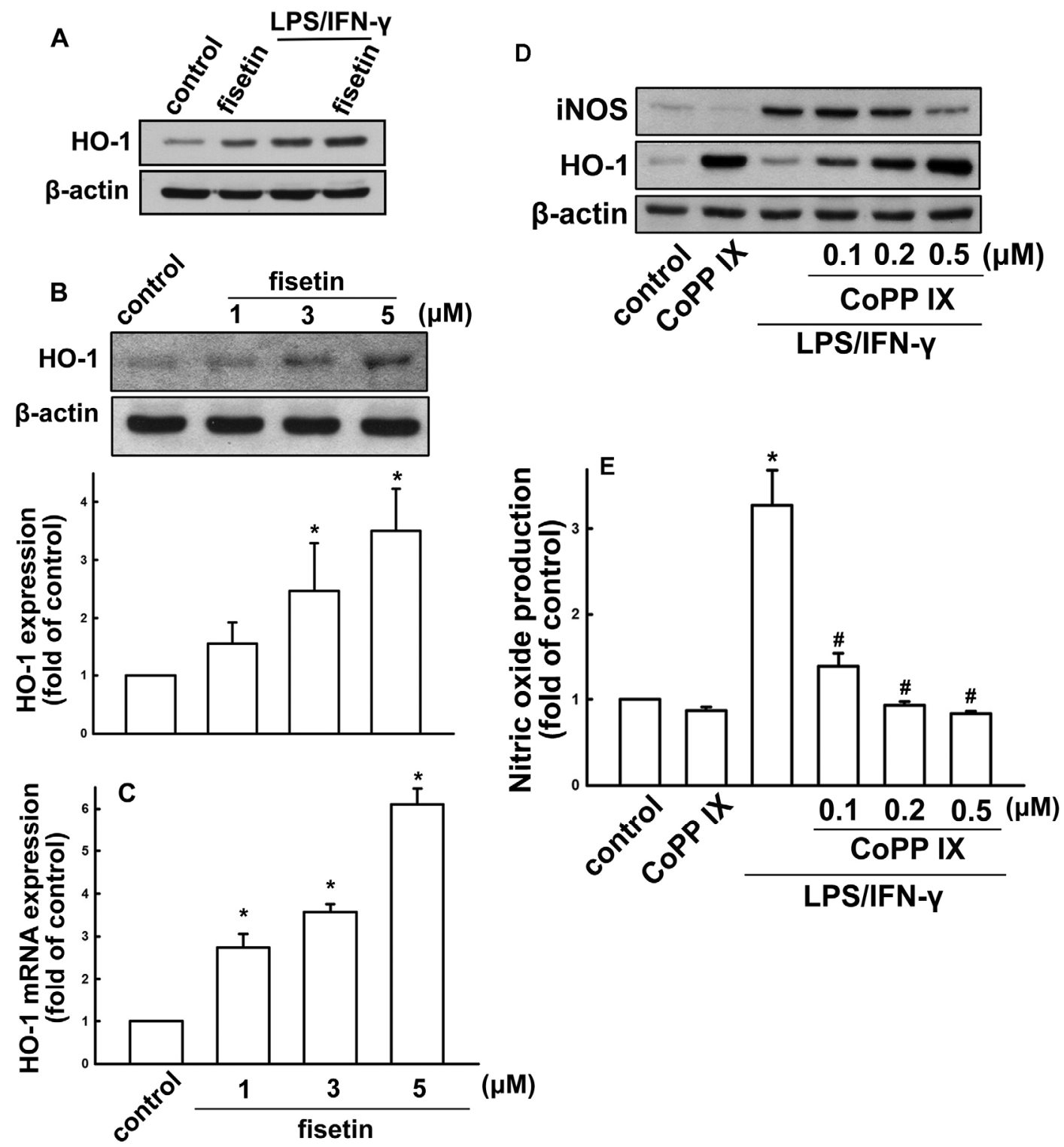


Figure 6. Involvement of p38 and Akt signaling pathways in fisetin-stimulated HO-1 up-regulation in BV-2 microglia. (A) Cells were pretreated with various inhibitors (PD98059, SB203580, SP600125 or LY294002) for $60 \mathrm{~min}$, followed by stimulation with fisetin for $24 \mathrm{~h}$. Cells were pretreated with various concentrations of SB203580 (B) or LY294002 (C) for $60 \mathrm{~min}$, followed by stimulation with fisetin for $24 \mathrm{~h}$. Whole cell lysis proteins was extracted and subjected to western blot analysis for HO-1 expression. Cells were incubated with fisetin for indicated periods $(5,10,30,60$ or $120 \mathrm{~min})$. Whole cell lysates were subjected to western blot analysis by using antibodies against the phosphorylated p38 (D) or Akt (E). Similar results were obtained from at least three independent experiments. ${ }^{*} p<0.05$ compared with the control group; ${ }^{\#} p<0.05$ compared with the fisetin treatment group.
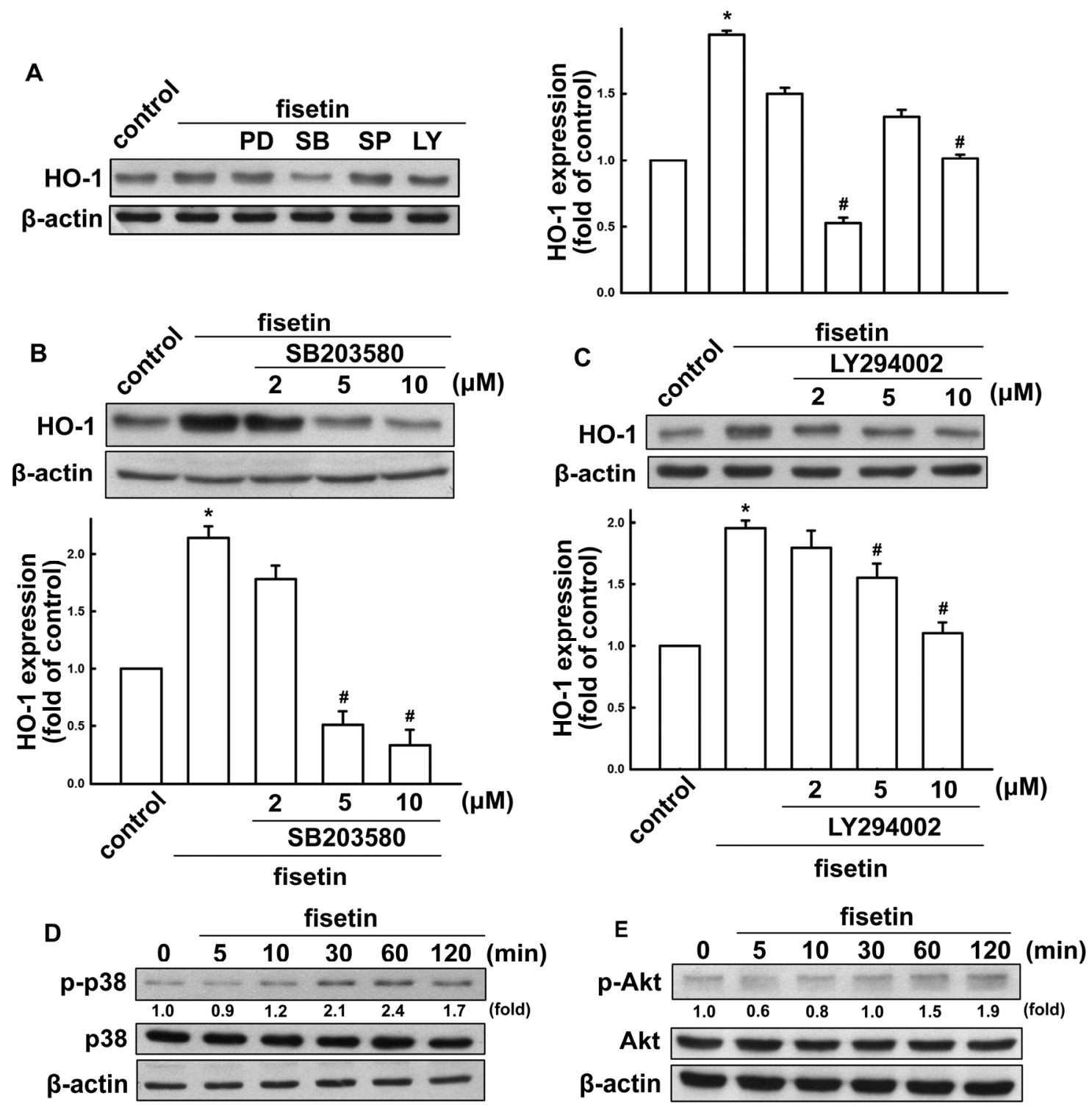

\subsection{Fisetin Inhibits Microglial Activation in a Mouse Model}

To determine the improvements induced by fisetin treatment on neuroinflammatory responses in vivo, we performed a motor behavior test and an immunohistochemical analysis. Mice were continuously 
administered fisetin for three consecutive days, and were then injected or not with LPS (Figure 7A). Motor balance and coordination function were analyzed using an accelerating rotarod test [34]. As shown in Figure 7B, LPS-treated mice showed a reduced latency in the rotarod test, thus demonstrating motor impairments compared to the control group. However, administration with fisetin significantly ameliorated the motor-impaired effects of LPS-injected mice (Figure 7B).

Figure 7. Fisetin prevents LPS-induced microglial activation. Mice received intraperitoneal injections of fisetin at concentrations of either 10 or $20 \mathrm{mg} / \mathrm{kg}$ once per day for 3 consecutive days. On the third day, fisetin treatment was followed with a single intraperitoneal injection of LPS $(20 \mathrm{mg} / \mathrm{kg})$. Motor balance and coordination function were analyzed using an accelerating rotarod test (B). Microglial morphology was visualized by anti-Iba-1 immunolabeling in cortical (C) and hippocampal (D) regions.

A

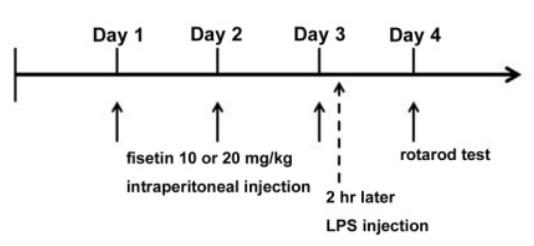

C cortex

control

$100 \mathrm{X}$

$400 X$

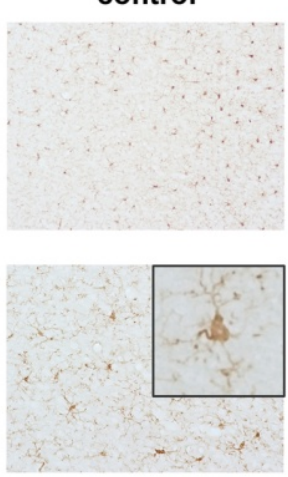

D hippocampus

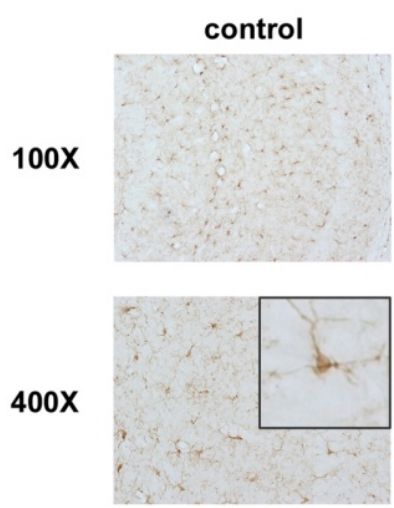

LPS
B

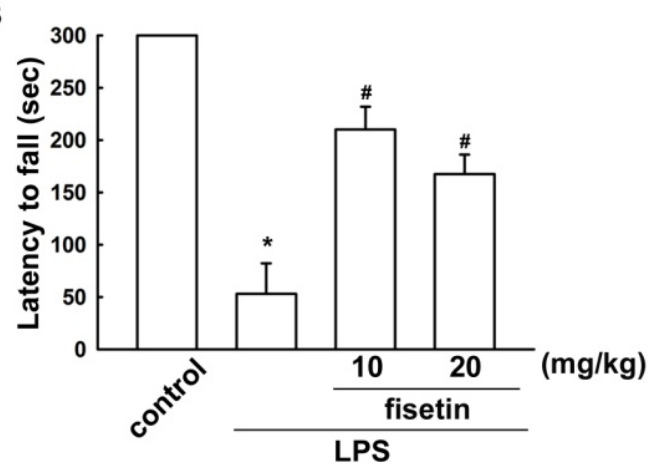

fisetin

(10 $\mathrm{mg} / \mathrm{kg})+$ LPS

fisetin
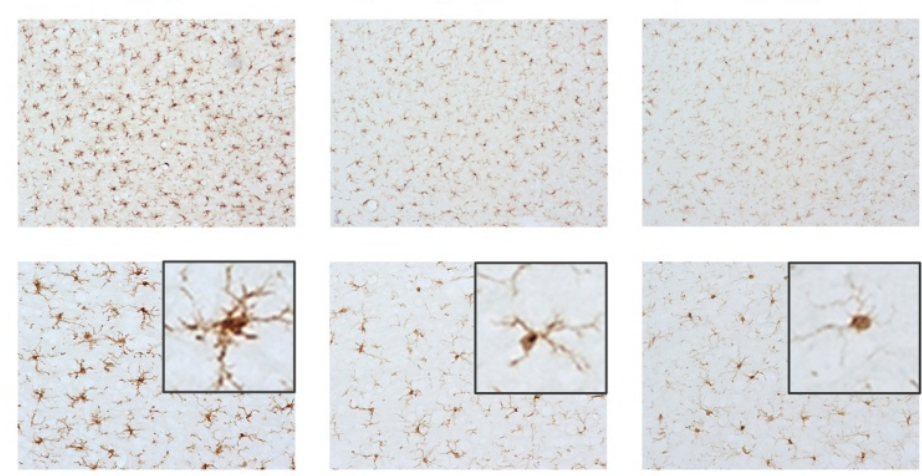

(20 mg/kg)+LPS

fisetin

(10 $\mathrm{mg} / \mathrm{kg})+$ LPS
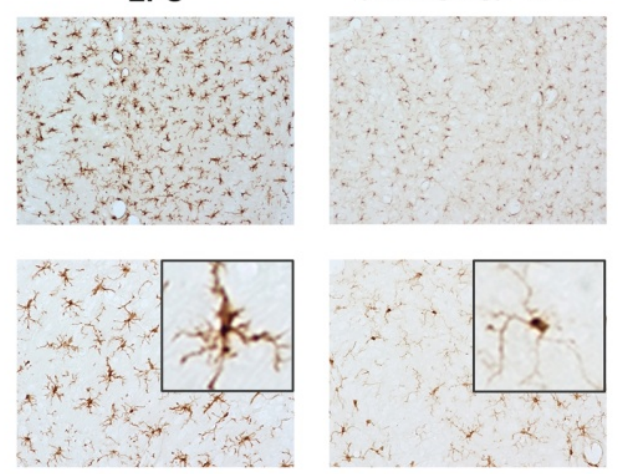

fisetin (20 $\mathrm{mg} / \mathrm{kg})+$ LPS

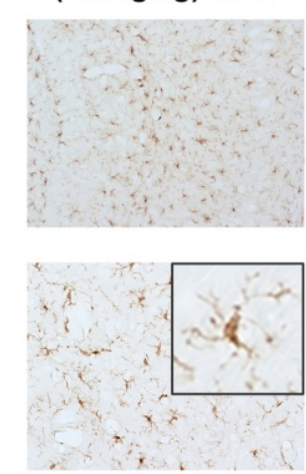


The activation of microglia was analyzed morphologically Iba-1 immunoreactivity by immunohistochemical analysis. After LPS injection for $24 \mathrm{~h}$, activated microglial cells were distributed throughout whole mouse brains. The Iba-1 positive immunoreactivity was much stronger in LPS-treated mice, microglial cells with pronounced hypertrophy and enlarger cell bodies compared with the control groups in cortical and hippocampal regions (Figure 7C,D). Similar to the motor behavioral results, microglial activation in the mice brains were effectively attenuated by administration of fisetin (Figure 7C,D).

\section{Discussion}

There were eight major findings of current study: (1) When microglia were exposed to $\mathrm{H}_{2} \mathrm{O}_{2}$, the intracellular ROS was highly increased, which was mitigated by fisetin. (2) Fisetin effectively inhibited ATP-induced increase microglial migratory activity. (3) LPS/IFN- $\gamma$ - or peptidoglycan-induced NO production were suppressed by treating fisetin to microglia. (4) Fisetin is nontoxic at $1-5 \mu \mathrm{M}$ and dose-dependently reduced iNOS and IL-1 $\beta$ productions. (5) LPS plus IFN- $\gamma$ enhanced STAT signaling activation was diminished by treatment with fisetin. (6) HO-1 levels were up-regulated by fisetin treatment dose-dependently. Treatment with HO-1 activator increased HO-1 expression and abrogated LPS/IFN- $\gamma$-induced iNOS/NO expressions. (7) Administration with fisetin significantly ameliorated the motor-impaired effects of LPS-injected mice. (8) Microglial activation in the mouse brain was effectively attenuated by administration of fisetin. Accordingly, fisetin was effective in retarding microglial activation. Fisetin potently inhibits oxidative reactions and proinflammatory responses in microglia, probably via promoting up-regulation of an endogenous antioxidant HO-1 expression.

Cytokines are important mediators involved in immune, inflammatory, and immunomodulatory functions [15]. Although inflammatory responses regulate normal functions of neuronal cells, microglial activation must be tightly control to avoid exaggerated nenurotoxicity [6,13]. Bacterial meningitis is the most frequently fatal infection in CNS, which results in significant neurological sequelae $[44,45]$. In Gram-negative infections, LPS is a well-known activator of microglia. Peptidoglycan, a major component of the Gram-positive bacterium cell wall, activates microglia and induces productions of chemokines and cytokines $[42,43,46]$. STAT1 is a key inflammatory signaling molecule to regulate iNOS expression in microglial cells and macrophages $[47,48]$. Activated microglial cells migrate to the neuronal injury sites and express inflammatory cytokines which aggravate neuronal damage [7-10]. In the present study, fisetin effectively inhibited microglial cell migration induced by ATP, and inflammatory cytokine expressions induced by both LPS/IFN- $\gamma$ and peptidoglycan stimulations.

Classical activation of macrophages/microglia by microbial compounds or pro-inflammatory cytokines yields a phenotype, which linked to neuroinflammation and neurotoxicity [49,50]. Otherwise, alternative activation of macrophages/microglia leads to anti-inflammatory phenotype [51-54], which generates neuronal growth factors as well as anti-inflammatory cytokines, thus contributing to neuroprotection [55-58]. Therefore, induction of alternative activation of macrophages/microglia and increases in anti-inflammatory cytokines may provide a novel strategy for anti-neuroinflammation and neuroprotection. HO-1 is known to be a potent anti-oxidative enzyme, the key mediators participating in signal transduction mechanisms remain to be fully identified. It has been reported that HO-1 may as a therapeutic target in neurodegenerative diseases and brain infections [59]. Our results support 
previous reports showing that HO-1 is a critical regulator of NO production in numerous cells $[60,61]$. Specifically, recent reports have shown that PI-3 kinase/Akt and p38 signaling pathways regulate HO-1 expression in various cells [62,63]. Again, our results from the microglial cells support the role of these pathways in fisetin-induced HO-1 expression. Specifically, fisetin activates Akt and p38 phosphorylation and the blockade of PI-3 kinase/AKT and p38 pathways antagonizes fisetin-induced HO-1 expression.

Intraperitoneal injection of LPS is a useful method for investigating inflammation-caused motor and coordination function deficits in rodent model. Peripheral inflammation exacerbates brain cytokine expression, leading to neurodegeneration [64], motor impairment [65], and cognitive impairment [66]. A recent study has shown that intraperitoneal injection of LPS induced progressive motor impairment from 4 to $24 \mathrm{~h}$ [65]. It has also been reported that peripheral LPS injection induced microglial activation and motor impairment [67]. In current study, we also performed an intraperitoneally injection of LPS, which caused a shorter latency on the rotarod test and microglia activation significantly in cortex and hippocampus; however, treatment with fisetin significantly alleviated these motor-impaired effects and microglia activation.

\section{Experimental}

\subsection{Reagents and Antibodies}

Recombinant murine IFN- $\gamma$ was purchased from PeproTech (Rocky Hill, NJ, USA). LPS from Escherichia coli Serotype 055:B5, SB203580, PD98059, SP600125 and LY294002 were obtained from Sigma-Aldrich (St. Louis, MO, USA). Peptidoglycan from Staphylococcus aureus was purchased from Fluka (Buchs, Switzerland). The antibody against ionized calcium binding adaptor molecule 1 (Iba 1) was purchased from Wako Pure Chemical Industries (Osaka, Japan). Primary antibodies against Akt, $\beta$-actin, phosphorylated Akt, STAT1 and p38 were purchased from Santa Cruz Biotechnology (Santa Cruz, CA, USA). HO-1 antibody was purchased from StressGen Biotechnologies (San Diego, CA, USA). Primary antibodies against phosphorylated p38 and STAT-1 phosphorylated at Tyr $^{701}$ were purchased from Cell Signaling and Neuroscience (Danvers, MA, USA). The primary antibody against iNOS was purchased from BD Transduction Lab (Lexington, KY, USA).

\subsection{Cell Culture}

The murine microglial cell BV-2 was generated from infecting primary microglial cell culture with a v-raf/v-myc oncogene carrying a retrovirus, and the cells retain the morphological, phenotypical, and functional properties of primary microglial cells [68]. Cells were cultured in DMEM (Gibco, Grand Island, NY, USA) with $10 \% \mathrm{FBS}$ at $37{ }^{\circ} \mathrm{C}$, incubated in a humidified atmosphere consisting of $5 \%$ $\mathrm{CO}_{2}$ and $95 \%$ air.

\subsection{Animals}

The animal experiments were accordance with the Animal Care and Use Guidelines of the China Medical University (Taichung, Taiwan). Eight-week-old male ICR mice were purchased from the National Laboratory Animal Center (Taipei, Taiwan). The mice were housed in a temperature- and 
humidity-controlled environment, and given free access to foods and water, and acclimated to their environment for at least 7 days before conducting the experiments.

\subsection{Tissue Preparation and Immunohistochemistry}

Mice received an intraperitoneal injection of saline or $20 \mathrm{mg} / \mathrm{kg}$ LPS. Twenty-four hours later, mice were deeply anesthetized with chloral hydrate and transcardially perfused with $10 \%$ formaldehyde. These brains were sliced coronal serial sections $(30 \mu \mathrm{M})$ using a freezing sliding microtome cryostat (CM305S, Leica, Microsystems; Wetzlar, Germany). Brain sections were quenched by endogenous peroxidases with hydrogen peroxide, blocked by nonspecific binding with goat serum, permeabilized with Triton X-100, and then incubated with a primary antibody against Iba-1. Following incubation with a biotin-conjugated secondary antibody, the sections were incubated with an avidin-biotin complex (Vector Laboratories, Burlingame, CA, USA), and labeling was visualized with diaminobenzidine. The cerebral cortex and hippocampus were digitally captured at $200 \times$ magnification using a light microscope.

\subsection{Reactive Oxygen Species (ROS) Assay}

The procedure of ROS assay was according to our previous studies. Production of ROS was assessed oxidation of specific probes with 2',7'-dichlorodihydrofluorescein diacetate $\left(\mathrm{H}_{2} \mathrm{DCFDA}\right)$ by using flow cytometry. Cells were incubated to $\mathrm{H}_{2}$ DCFDA $(10 \mu \mathrm{M})$ for $30 \mathrm{~min}$ at $37{ }^{\circ} \mathrm{C}$, and then stimulated with hydrogen peroxide. The fluorescence intensity was measured with an excitation filter of 488 and $525 \mathrm{~nm}$ emission wavelengths.

\subsection{Western Blot Analysis}

Western blotting was performed according to our previous report [69,70]. Briefly, cells were lysed in a homogenization buffer and equal amounts of the samples were loaded in a SDS-PAGE membrane. The membranes were probed with a primary antibody and then incubated with a peroxidase-conjugated secondary antibody. The blots were developed by a western chemiluminescent HRP substrate (Millipore, Billerica, MA, USA) and visualized by using Fuji medical X-ray film (Fujifilm, Tokyo, Japan). The blots were then stripped by using a stripping buffer [71] and re-probed anti- $\beta$-actin antibody to as a loading control.

\subsection{Migration Assay}

In vitro migration assay was performed using Costar Transwell inserts (pore size: $8 \mu \mathrm{m}$; Corning, Albany, NY, USA) in 24-well plates as described previously [72]. Approximately $1 \times 10^{4}$ cells in $200 \mu \mathrm{L}$ of medium were placed in the upper chamber, and the same medium containing ATP was placed in the lower chamber $[34,73]$. Before performing the migration assay, cells were pre-treated for 60 min with fisetin followed by treatment with ATP during the 24 -h migration assay (incubated at $37{ }^{\circ} \mathrm{C}$ in $5 \%$ $\mathrm{CO}_{2}$ ). After the $24-\mathrm{h}$ assay, the cells were stained with $0.05 \%$ crystal violet and $2 \%$ methanol. Non-migratory cells on the upper surface of the filters were removed by wiping with a cotton swab. 
Cell number was counted in five random fields per well under a microscope at $200 \times$ magnification. Images of migratory cells were observed and acquired using a digital camera and light microscope.

\subsection{Quantitative Real-Time PCR}

Quantitative real-time PCR was performed according to our previous report [35,38]. Briefly, quantitative real-time PCR using SYBR Green Master Mix was performed with StepOne Plus System (Applied Biosystems, Singapore). After incubation at $50{ }^{\circ} \mathrm{C}$ for $2 \mathrm{~min}$ and $95{ }^{\circ} \mathrm{C}$ for $10 \mathrm{~min}$, the PCR was performed as follows: 40 cycles at $95{ }^{\circ} \mathrm{C}$ for $10 \mathrm{~s}$ and $60{ }^{\circ} \mathrm{C}$ for $1 \mathrm{~min}$. The threshold was set above the non-template control background and within the linear phase of target gene amplification to calculate the cycle number at which the transcript was detected (denoted as CT).

\subsection{Nitric Oxide Assay}

Nitric oxide production was analyzed by measuring nitrite content in culture media as described in our previous report [46]. Briefly, the media were determined by a colorimetric assay with a Griess reaction, the absorbance was determined at $550 \mathrm{~nm}$ using a microplate reader (Thermo Scientific, Vantaa, Finland).

\subsection{3-(4,5-Dimethylthiazol-2-yl)-2,5-diphenyltetrazolium Bromide (MTT) Assay}

Cell viability was determined using the MTT assay, the procedure was according to previous reports [74]. After treatment with fisetin for $24 \mathrm{~h}$, cell culture media were removed. MTT $(0.5 \mathrm{mg} / \mathrm{mL})$ was added to each culture well and the mixture was incubated for $2 \mathrm{~h}$ at $37{ }^{\circ} \mathrm{C}$. The MTT reagent was removed and washed with PBS for several times. DMSO $(200 \mu \mathrm{L}$ per well) was added to dissolve formazan crystals, absorbance was determined at $550 \mathrm{~nm}$ using a microplate reader (Thermo Scientific, Vantaa, Finland).

\subsection{Statistical Analyses}

The values are reported as mean \pm S.E.M. Statistical analyses for two groups were performed using Student's $t$-test. The difference was determined to be significant if the $p$ value was $<0.05$.

\section{Conclusions}

The results of current study suggest that fisetin exerts both anti-oxidative and anti-inflammatory activities may be suggested as a promising strategy in the treatment of neurodegenerative diseases.

\section{Acknowledgments}

This work is supported in part by grants from the National Science Council (NSC 101-2320-B-039048-MY2, NSC 102-2320-B-039-051-MY3, NSC 102-2314-B-303-006- and NSC 102-2320-B-039026-MY3), China Medical University (CMU101-ASIA-10), Taiwan Ministry of Health and Welfare Clinical Trial and Research Center of Excellence (DOH102-TD-B-111-004), and Taichung Tzu Chi General Hospital (TTCRD 102-11). The authors thank S. H. Ko for technical support. 


\section{Author Contributions}

J.-Y. Chuang, P.-C. Chang, C.-F. Tsai, and D.-Y. Lu designed the research; W.-L. Yeh, C. Lin, and D.-Y. Lu wrote the paper; Y.-C. Shen, L.-S. Wu, H.-Y. Lin and Y.-S. Liu performed experiments; Y.-C. Shen, P.-C. Chang, C.-F. Tsai, and J.-H. Chen analyzed results.

\section{Conflicts of Interest}

The authors declare no conflict of interest.

\section{References}

1. Czeh, M.; Gressens, P.; Kaindl, A.M. The yin and yang of microglia. Dev. Neurosci. 2011, 33, 199-209.

2. Wee Yong, V. Inflammation in neurological disorders: A help or a hindrance? Neuroscientist 2010, 16, 408-420.

3. Ziv, Y.; Ron, N.; Butovsky, O.; Landa, G.; Sudai, E.; Greenberg, N.; Cohen, H.; Kipnis, J.; Schwartz, M. Immune cells contribute to the maintenance of neurogenesis and spatial learning abilities in adulthood. Nat. Neurosci. 2006, 9, 268-275.

4. Koizumi, S.; Ohsawa, K.; Inoue, K.; Kohsaka, S. Purinergic receptors in microglia: Functional modal shifts of microglia mediated by $\mathrm{P} 2$ and P1 receptors. Glia 2013, 61, 47-54.

5. Gibson, G.E.; Zhang, H. Abnormalities in oxidative processes in non-neuronal tissues from patients with Alzheimer's disease. J. Alzheimers Dis. 2001, 3, 329-338.

6. Maa, M.C. Infectious diseases: A never-ending threat. BioMedicine 2013, 3, 1.

7. Loihl, A.K.; Murphy, S. Expression of nitric oxide synthase-2 in glia associated with CNS pathology. Prog. Brain Res. 1998, 118, 253-267.

8. Bal-Price, A.; Brown, G.C. Inflammatory neurodegeneration mediated by nitric oxide from activated glia-inhibiting neuronal respiration, causing glutamate release and excitotoxicity. J. Neurosci. 2001, 21, 6480-6491.

9. Beckman, J.S.; Chen, J.; Crow, J.P.; Ye, Y.Z. Reactions of nitric oxide, superoxide and peroxynitrite with superoxide dismutase in neurodegeneration. Prog. Brain Res. 1994, 103, 371-380.

10. Chao, C.C.; Hu, S.; Peterson, P.K. Modulation of human microglial cell superoxide production by cytokines. J. Leukoc. Biol. 1995, 58, 65-70.

11. Wang, J.Y.; Shum, A.Y.; Ho, Y.J.; Wang, J.Y. Oxidative neurotoxicity in rat cerebral cortex neurons: Synergistic effects of $\mathrm{H}_{2} \mathrm{O}_{2}$ and $\mathrm{NO}$ on apoptosis involving activation of p38 mitogen-activated protein kinase and caspase-3. J. Neurosci. Res. 2003, 72, 508-519.

12. Knott, C.; Stern, G.; Wilkin, G.P. Inflammatory regulators in Parkinson's disease: iNOS, lipocortin-1, and cyclooxygenases-1 and -2. Mol. Cell. Neurosci. 2000, 16, 724-739.

13. Hudson, C.C.; Liu, M.; Chiang, G.G.; Otterness, D.M.; Loomis, D.C.; Kaper, F.; Giaccia, A.J.; Abraham, R.T. Regulation of hypoxia-inducible factor 1alpha expression and function by the mammalian target of rapamycin. Mol. Cell. Biol. 2002, 22, 7004-7014. 
14. Dinarello, C.A. Immunological and inflammatory functions of the interleukin-1 family. Annu. Rev. Immunol. 2009, 27, 519-550.

15. Su, P.Y.; Liu, S.J.; Chen, Y.H.; Wu, S.S.; Chen, Y.L.; Ke, J.R.; Peng, C.Y.; Sher, Y.P. Increased IL-8 and IL-1 $\beta$ in the bile of acute cholecystitis patients. BioMedicine 2013, 3, 181-155.

16. Cunningham, C. Microglia and neurodegeneration: The role of systemic inflammation. Glia 2013, $61,71-90$.

17. Rossi, S.; Furlan, R.; de Chiara, V.; Motta, C.; Studer, V.; Mori, F.; Musella, A.; Bergami, A.; Muzio, L.; Bernardi, G.; et al. Interleukin-1beta causes synaptic hyperexcitability in multiple sclerosis. Ann. Neurol. 2012, 71, 76-83.

18. Li, C.C.; Lo, H.Y.; Hsiang, C.Y.; Ho, T.Y. DNA microarray analysis as a tool to investigate the therapeutic mechanisms and drug development of Chinese medicinal herbs. Biomedicine 2012, 2, $10-16$.

19. Tsai, C.W.; Chen, H.W.; Sheen, L.Y.; Lii, K.C. Garlic: Health benefits and actions. Biomedicine 2012, 2, 17-29.

20. Tang, F.Y. The silver bullet for cancer prevention: Chemopreventive effects of carotenoids. Biomedicine 2012, 2, 117-121.

21. Adhami, V.M.; Syed, D.N.; Khan, N.; Mukhtar, H. Dietary flavonoid fisetin: A novel dual inhibitor of PI3K/Akt and mTOR for prostate cancer management. Biochem. Pharmacol. 2012, $84,1277-1281$.

22. Ishige, K.; Schubert, D.; Sagara, Y. Flavonoids protect neuronal cells from oxidative stress by three distinct mechanisms. Free Radic. Biol. Med. 2001, 30, 433-446.

23. Khan, N.; Syed, D.N.; Ahmad, N.; Mukhtar, H. Fisetin: A dietary antioxidant for health promotion. Antioxid. Redox Signal. 2013, 19, 151-162.

24. Zbarsky, V.; Datla, K.P.; Parkar, S.; Rai, D.K.; Aruoma, O.I.; Dexter, D.T. Neuroprotective properties of the natural phenolic antioxidants curcumin and naringenin but not quercetin and fisetin in a 6-OHDA model of Parkinson's disease. Free Radic. Res. 2005, 39, 1119-1125.

25. Zheng, L.T.; Ock, J.; Kwon, B.M.; Suk, K. Suppressive effects of flavonoid fisetin on lipopolysaccharide-induced microglial activation and neurotoxicity. Int. Immunopharmacol. 2008, $8,484-494$.

26. Chiruta, C.; Schubert, D.; Dargusch, R.; Maher, P. Chemical modification of the multitarget neuroprotective compound fisetin. J. Med. Chem. 2012, 55, 378-389.

27. Gelderblom, M.; Leypoldt, F.; Lewerenz, J.; Birkenmayer, G.; Orozco, D.; Ludewig, P.; Thundyil, J.; Arumugam, T.V.; Gerloff, C.; Tolosa, E.; et al. The flavonoid fisetin attenuates postischemic immune cell infiltration, activation and infarct size after transient cerebral middle artery occlusion in mice. J. Cereb. Blood Flow Metab. 2012, 32, 835-843.

28. Prakash, D.; Gopinath, K.; Sudhandiran, G. Fisetin enhances behavioral performances and attenuates reactive gliosis and inflammation during aluminum chloride-induced neurotoxicity. Neuromol. Med. 2013, 15, 192-208.

29. Jazwa, A.; Cuadrado, A. Targeting heme oxygenase-1 for neuroprotection and neuroinflammation in neurodegenerative diseases. Curr. Drug Targets 2010, 11, 1517-1531. 
30. Jeong, G.S.; Lee, D.S.; Li, B.; Lee, H.J.; Kim, E.C.; Kim, Y.C. Effects of sappanchalcone on the cytoprotection and anti-inflammation via heme oxygenase-1 in human pulp and periodontal ligament cells. Eur. J. Pharmacol. 2010, 644, 230-237.

31. Tsoyi, K.; Jang, H.J.; Lee, Y.S.; Kim, Y.M.; Kim, H.J.; Seo, H.G.; Lee, J.H.; Kwak, J.H.; Lee, D.U.; Chang, K.C. $(+)-$ Nootkatone and $(+)$-valencene from rhizomes of Cyperus rotundus increase survival rates in septic mice due to heme oxygenase-1 induction. J. Ethnopharmacol. 2011, 137, 1311-1317.

32. Choy, C.S.; Hu, C.M.; Chiu, W.T.; Lam, C.S.; Ting, Y.; Tsai, S.H.; Wang, T.C. Suppression of lipopolysaccharide-induced of inducible nitric oxide synthase and cyclooxygenase-2 by Sanguis Draconis, a dragon's blood resin, in RAW 264.7 cells. J. Ethnopharmacol. 2008, 115, 455-462.

33. Choi, H.G.; Lee, D.S.; Li, B.; Choi, Y.H.; Lee, S.H.; Kim, Y.C. Santamarin, a sesquiterpene lactone isolated from Saussurea lappa, represses LPS-induced inflammatory responses via expression of heme oxygenase-1 in murine macrophage cells. Int. Immunopharmacol. 2012, 13, 271-279.

34. Lu, D.Y.; Huang, B.R.; Yeh, W.L.; Lin, H.Y.; Huang, S.S.; Liu, Y.S.; Kuo, Y.H. Anti-neuroinflammatory effect of a novel caffeamide derivative, KS370G, in microglial cells. Mol. Neurobiol. 2013, 48, 863-874.

35. Lin, H.Y.; Huang, B.R.; Yeh, W.L.; Lee, C.H.; Huang, S.S.; Lai, C.H.; Lin, H.; Lu, D.Y. Antineuroinflammatory effects of lycopene via activation of adenosine monophosphate-activated protein kinase-alpha1/heme oxygenase-1 pathways. Neurobiol. Aging 2014, 35, 191-202.

36. Chen, J.H.; Huang, S.M.; Tan, T.W.; Lin, H.Y.; Chen, P.Y.; Yeh, W.L.; Chou, S.C.; Tsai, C.F.; Wei, I.H.; Lu, D.Y. Berberine induces heme oxygenase-1 up-regulation through phosphatidylinositol 3-kinase/AKT and NF-E2-related factor-2 signaling pathway in astrocytes. Int. Immunopharmacol. 2012, 12, 94-100.

37. Lu, D.Y.; Chen, J.H.; Tan, T.W.; Huang, C.Y.; Yeh, W.L.; Hsu, H.C. Resistin protects against 6-hydroxydopamine-induced cell death in dopaminergic-like MES23.5 cells. J. Cell. Physiol. 2013, 228, 563-571.

38. Lin, H.Y.; Yeh, W.L.; Huang, B.R.; Lin, C.; Lai, C.H.; Lin, H.; Lu, D.Y. Desipramine protects neuronal cell death and induces heme oxygenase-1 expression in Mes23.5 dopaminergic neurons. PLoS One 2012, 7, e50138.

39. Hanneken, A.; Lin, F.F.; Johnson, J.; Maher, P. Flavonoids protect human retinal pigment epithelial cells from oxidative-stress-induced death. Investig. Ophthalmol. Vis. Sci. 2006, 47, 3164-3177.

40. Lee, S.E.; Jeong, S.I.; Yang, H.; Park, C.S.; Jin, Y.H.; Park, Y.S. Fisetin induces Nrf2-mediated HO-1 expression through PKC-delta and p38 in human umbilical vein endothelial cells. J. Cell. Biochem. 2011, 112, 2352-2360.

41. Sakai, E.; Shimada-Sugawara, M.; Yamaguchi, Y.; Sakamoto, H.; Fumimoto, R.; Fukuma, Y.; Nishishita, K.; Okamoto, K.; Tsukuba, T. Fisetin inhibits osteoclastogenesis through prevention of RANKL-induced ROS production by Nrf2-mediated up-regulation of phase II antioxidant enzymes. J. Pharmacol. Sci. 2013, 121, 288-298. 
42. Lin, H.Y.; Tang, C.H.; Chen, J.H.; Chuang, J.Y.; Huang, S.M.; Tan, T.W.; Lai, C.H.; Lu, D.Y. Peptidoglycan induces interleukin- 6 expression through the TLR2 receptor, JNK, c-Jun, and AP-1 pathways in microglia. J. Cell. Physiol. 2011, 226, 1573-1582.

43. Lin, H.Y.; Tang, C.H.; Chen, Y.H.; Wei, I.H.; Chen, J.H.; Lai, C.H.; Lu, D.Y. Peptidoglycan enhances proinflammatory cytokine expression through the TLR2 receptor, MyD88, phosphatidylinositol 3-kinase/AKT and NF-kappaB pathways in BV-2 microglia. Int. Immunopharmacol. 2010, 10, 883-891.

44. Schut, E.S.; de Gans, J.; van de Beek, D. Community-acquired bacterial meningitis in adults. Pract. Neurol. 2008, 8, 8-23.

45. Schleifer, K.H.; Kandler, O. Peptidoglycan types of bacterial cell walls and their taxonomic implications. Bacteriol. Rev. 1972, 36, 407-477.

46. Huang, B.R.; Tsai, C.F.; Lin, H.Y.; Tseng, W.P.; Huang, S.S.; Wu, C.R.; Lin, C.; Yeh, W.L.; $\mathrm{Lu}, \mathrm{D} . \mathrm{Y}$. Interaction of inflammatory and anti-inflammatory responses in microglia by Staphylococcus aureus-derived lipoteichoic acid. Toxicol. Appl. Pharmacol. 2013, 269, 43-50.

47. Alamuru, N.P.; Behera, S.; Butchar, J.P.; Tridandapani, S.; Kaimal Suraj, S.; Babu, P.P.; Hasnain, S.E.; Ehtesham, N.Z.; Parsa, K.V. A novel immunomodulatory function of PHLPP1: Inhibition of iNOS via attenuation of STAT1 ser727 phosphorylation in mouse macrophages. J. Leukocyte Biol. 2014, 95, 775-783.

48. Liu, P.W.; Chen, M.F.; Tsai, A.P.; Lee, T.J. STAT1 mediates oroxylin a inhibition of iNOS and pro-inflammatory cytokines expression in microglial BV-2 cells. PLoS One 2012, 7, e50363.

49. Bal-Price, A.; Matthias, A.; Brown, G.C. Stimulation of the NADPH oxidase in activated rat microglia removes nitric oxide but induces peroxynitrite production. J. Neurochem. 2002, 80, 73-80.

50. Gebicke-Haerter, P.J. Microglia in neurodegeneration: Molecular aspects. Microsc. Res. Tech. 2001, 54, 47-58.

51. Seledtsov, V.I.; Seledtsova, G.V. A balance between tissue-destructive and tissue-protective immunities: A role of toll-like receptors in regulation of adaptive immunity. Immunobiology 2012, $217,430-435$.

52. Sica, A.; Mantovani, A. Macrophage plasticity and polarization: In vivo veritas. J. Clin. Investig. 2012, 122, 787-795.

53. Van Ginderachter, J.A.; Movahedi, K.; Hassanzadeh Ghassabeh, G.; Meerschaut, S.; Beschin, A.; Raes, G.; de Baetselier, P. Classical and alternative activation of mononuclear phagocytes: Picking the best of both worlds for tumor promotion. Immunobiology 2006, 211, 487-501.

54. Martinez, F.O. Regulators of macrophage activation. Eur. J. Immunol. 2011, 41, 1531-1534.

55. Hanisch, U.K.; Kettenmann, H. Microglia: Active sensor and versatile effector cells in the normal and pathologic brain. Nat. Neurosci. 2007, 10, 1387-1394.

56. Gordon, S. Alternative activation of macrophages. Nat. Rev. Immunol. 2003, 3, 23-35.

57. Schwartz, M.; Butovsky, O.; Bruck, W.; Hanisch, U.K. Microglial phenotype: Is the commitment reversible? Trends Neurosci. 2006, 29, 68-74.

58. Michelucci, A.; Heurtaux, T.; Grandbarbe, L.; Morga, E.; Heuschling, P. Characterization of the microglial phenotype under specific pro-inflammatory and anti-inflammatory conditions: Effects of oligomeric and fibrillar amyloid-beta. J. Neuroimmunol. 2009, 210, 3-12. 
59. Cuadrado, A.; Rojo, A.I. Heme oxygenase-1 as a therapeutic target in neurodegenerative diseases and brain infections. Curr. Pharm. Des. 2008, 14, 429-442.

60. Tsoyi, K.; Kim, H.J.; Shin, J.S.; Kim, D.H.; Cho, H.J.; Lee, S.S.; Ahn, S.K.; Yun-Choi, H.S.; Lee, J.H.; Seo, H.G.; et al. HO-1 and JAK-2/STAT-1 signals are involved in preferential inhibition of iNOS over COX-2 gene expression by newly synthesized tetrahydroisoquinoline alkaloid, CKD712, in cells activated with lipopolysacchride. Cell. Signal. 2008, 20, 1839-1847.

61. Vareille, M.; Rannou, F.; Thelier, N.; Glasser, A.L.; de Sablet, T.; Martin, C.; Gobert, A.P. Heme oxygenase-1 is a critical regulator of nitric oxide production in enterohemorrhagic Escherichia coli-infected human enterocytes. J. Immunol. 2008, 180, 5720-5726.

62. Lee, J.W.; Bae, C.J.; Choi, Y.J.; Kim, S.I.; Kwon, Y.S.; Lee, H.J.; Kim, S.S.; Chun, W. 3,4,5-Trihydroxycinnamic acid inhibits lipopolysaccharide (LPS)-induced inflammation by Nrf2 activation in vitro and improves survival of mice in LPS-induced endotoxemia model in vivo. Mol. Cell. Biochem. 2014, 390, 143-153.

63. Tsai, H.Y.; Huang, P.H.; Lin, F.Y.; Chen, J.S.; Lin, S.J.; Chen, J.W. Ginkgo biloba extract reduces high-glucose-induced endothelial reactive oxygen species generation and cell adhesion molecule expression by enhancing HO-1 expression via Akt/eNOS and p38 MAP kinase pathways. Eur. J. Pharm. Sci. 2013, 48, 803-811.

64. Qin, L.; Wu, X.; Block, M.L.; Liu, Y.; Breese, G.R.; Hong, J.S.; Knapp, D.J.; Crews, F.T. Systemic LPS causes chronic neuroinflammation and progressive neurodegeneration. Glia 2007, $55,453-462$.

65. Jang, E.; Lee, S.; Kim, J.H.; Seo, J.W.; Lee, W.H.; Mori, K.; Nakao, K.; Suk, K. Secreted protein lipocalin-2 promotes microglial M1 polarization. FASEB J. 2013, 27, 1176-1190.

66. Bossu, P.; Cutuli, D.; Palladino, I.; Caporali, P.; Angelucci, F.; Laricchiuta, D.; Gelfo, F.; de Bartolo, P.; Caltagirone, C.; Petrosini, L. A single intraperitoneal injection of endotoxin in rats induces long-lasting modifications in behavior and brain protein levels of TNF-alpha and IL-18. J. Neuroinflamm. 2012, 9, 101.

67. Franciosi, S.; Ryu, J.K.; Shim, Y.; Hill, A.; Connolly, C.; Hayden, M.R.; McLarnon, J.G.; Leavitt, B.R. Age-dependent neurovascular abnormalities and altered microglial morphology in the YAC128 mouse model of Huntington disease. Neurobiol. Dis. 2012, 45, 438-449.

68. Blasi, E.; Barluzzi, R.; Bocchini, V.; Mazzolla, R.; Bistoni, F. Immortalization of murine microglial cells by a v-raf/v-myc carrying retrovirus. J. Neuroimmunol. 1990, 27, 229-237.

69. Huang, S.M.; Chen, T.S.; Chiu, C.M.; Chang, L.K.; Liao, K.F.; Tan, H.M.; Yeh, W.L.; Chang, G.R.; Wang, M.Y.; Lu, D.Y. GDNF increases cell motility in human colon cancer through VEGF-VEGFR1 interaction. Endocr. Relat. Cancer 2014, 21, 73-84.

70. Chuang, J.Y.; Tsai, C.F.; Chang, S.W.; Chiang, I.P.; Huang, S.M.; Lin, H.Y.; Yeh, W.L.; Lu, D.Y. Glial cell line-derived neurotrophic factor induces cell migration in human oral squamous cell carcinoma. Oral. Oncol. 2013, 49, 1103-1112.

71. Huang, S.M.; Cheung, C.W.; Chang, C.S.; Tang, C.H.; Liu, J.F.; Lin, Y.H.; Chen, J.H.; Ko, S.H.; Wong, K.L.; Lu, D.Y. Phloroglucinol derivative MCPP induces cell apoptosis in human colon cancer. J. Cell. Biochem. 2011, 112, 643-652. 
72. Lu, D.Y.; Chang, C.S.; Yeh, W.L.; Tang, C.H.; Cheung, C.W.; Leung, Y.M.; Liu, J.F.; Wong, K.L. The novel phloroglucinol derivative BFP induces apoptosis of glioma cancer through reactive oxygen species and endoplasmic reticulum stress pathways. Phytomedicine 2012, 19, 1093-1100.

73. Huang, B.R.; Chang, P.C.; Yeh, W.L.; Lee, C.H.; Tsai, C.F.; Lin, C.; Lin, H.Y.; Liu, Y.S.; Wu, C.Y.; Ko, P.Y.; et al. Anti-neuroinflammatory effects of the calcium channel blocker nicardipine on microglial cells: implications for neuroprotection. PLoS One 2014, 9, e91167.

74. Tsai, C.F.; Yeh, W.L.; Chen, J.H.; Lin, C.; Huang, S.S.; Lu, D.Y. Osthole suppresses the migratory ability of human glioblastoma multiforme cells via inhibition of focal adhesion kinasemediated matrix metalloproteinase-13 expression. Int. J. Mol. Sci. 2014, 15, 3889-903.

Sample Availability: Not available.

(C) 2014 by the authors; licensee MDPI, Basel, Switzerland. This article is an open access article distributed under the terms and conditions of the Creative Commons Attribution license (http://creativecommons.org/licenses/by/3.0/). 